\title{
Short communication: Calving site selection of multiparous, group-housed dairy cows is influenced by site of a previous calving
}

\author{
M. V. Rørvang, ${ }^{* 1}$ B. L. Nielsen, $†$ M. S. Herskin, ${ }^{*}$ and M. B. Jensen* \\ *Department of Animal Science, Aarhus University, Blichers Allé 20, 8830 Tjele, Denmark \\ †INRA, NeuroBiologie de I'Olfaction, Université Paris-Saclay, 78350 Jouy-en-Josas, France
}

\begin{abstract}
A calving cow and her newborn calf appear to have an attracting effect on periparturient cows, which may potentially influence the functionality of future motivation-based calving pen designs. In this pilot study we examined whether calving site selection of grouphoused Holstein dairy cows was affected by the site of a previous calving. Ten multiparous cows moved to 1 of 2 group pens 11 (range $=4-27$ ) d before calving were included. Each pen consisted of an open area $(9 \times$ $9 \mathrm{~m})$ connected to 6 secluded areas $(4.5 \times 3 \mathrm{~m}$ each $)$, where cows could move freely between all areas. Time of calving, location of the breaking of the amniotic sac, as well as the place of birth were recorded. In all but 1 case cows calved within a distance of 1 cow length from where the previous calving took place, suggesting that the cows did not select calving site at random. These preliminary observations indicate that choice of calving site may be affected by the site of a previous calving, potentially explained by the presence of amniotic fluids. Key words: parturition, maternal behavior, cow preference, calving site selection
\end{abstract}

\section{Short Communication}

The use of motivation-based calving facilities may potentially increase cow welfare in modern dairy production. Based on the preferences of calving cows to seek isolation from the group (Proudfoot et al., 2014) and the finding that moving a calving cow to an individual pen late in the birth process may lead to prolonged calving (Proudfoot et al., 2013), a motivation-based calving facility may consist of a group pen joined to single calving pens into which cows can withdraw when calving is imminent (Rørvang and Jensen, 2016). However, calving site selection is likely to be influenced by factors other than motivation for isolation, knowledge

Received June 29, 2016.

Accepted October 11, 2016.

${ }^{1}$ Corresponding author: Maria.VilainRorvang@anis.au.dk of which may be needed to ensure the functionality of motivation-based calving pen designs. Campler et al. (2014) indicated that cows prefer to calve on sand over rubber, most likely because sand better supports the frequent changes in posture (Bak et al., 2016) seen during the final $6 \mathrm{~h}$ before calving (Miedema et al., 2011; Jensen, 2012). In lactating dairy cows various factors, such as depth of straw bedding (Tucker et al., 2009), dryness of bedding (Reich et al., 2010), and design of the lying area (Abade et al., 2015), influence where and for how long the cows prefer to lie down. At present, similar knowledge is not available for cows approaching calving. Edwards (1983) showed that calving cows, as well as newborn calves, seem to have an attracting effect on cows in late pregnancy, which may be mediated by the presence of amniotic fluid, known to contain olfactory cues and to facilitate maternal behavior in many mammalian species [e.g., rodents (Kristal, 1991), sheep (Lévy et al., 1983), dogs (Dunbar et al., 1981), cats, horses, pigs, and goats (Fabre-Nys et al., 1993)]. In addition to the presence of calving cows and calves, periparturient cows have been shown to be attracted to amniotic fluids (Pinheiro Machado et al., 1997). However, irrespective of the underlying mechanisms, knowledge about factors influencing calving site selection is important for the successful development of motivation-based calving facilities. Thus, the objective of the present study was to investigate whether calving site selection in group-housed dairy cows was influenced by the site of a previous calving.

The study took place at the Danish Cattle Research facility at AU Foulum (Aarhus University, Tjele, Denmark) in September 2015 and was originally planned as a pilot study before a larger experiment on calving behavior of dairy cows. Twelve multiparous Danish Holstein dairy cows (mean parity \pm SD: $2.2 \pm 0.4$ ) participated in the study. Prior to calving, the cows were allocated to 1 of 2 groups (I and II) with approximately equal dispersion of expected calving dates (average of $2 \mathrm{~d}$ between each calving). Each group was moved to a calving area in the experimental barn (calving areas 1 and 2 in Figure 1) approximately 1 wk before the first expected calving date in the group. Each calving area 
included an open area $(9 \times 9 \mathrm{~m})$ with 6 individual feed bins (each $75 \mathrm{~cm}$ wide; Jyden, Vemb, Denmark) and 6 adjoining secluded areas $(4.5 \times 3 \mathrm{~m}$ each $)$. Each secluded area was surrounded by 3 solid $1.8-\mathrm{m}$ walls, with one wall having the entrance (1.5 m wide) from the open area. The fourth side was a metal gate with a feed bunk (model: 1318-8210; Jyden). The freely accessible but secluded areas offered the cows an opportunity to calve more isolated than when within the group pen area. The whole calving area was bedded with $15 \mathrm{~cm}$ of sand (Kosand brand; Dansand, Brædstrup, Denmark; mean grain size $=0.322 \mathrm{~mm}$ ) topped with approximately 15 $\mathrm{cm}$ of barley straw bedding. Two water bowls (model: 2177-4010; Jyden) were located in the open area and one in each of the secluded areas.

All cows had ad libitum access to a TMR with a forage-to-concentrate ratio of 80:20 (DM basis). Feed was provided twice daily, between 0930 and $1200 \mathrm{~h}$ and between 1730 and $1800 \mathrm{~h}$. After calving, the cow and calf were removed from the barn within $12 \mathrm{~h}$ after calving.
All areas had feces removed and straw added on a daily basis (between 0930 and $1200 \mathrm{~h}$ ) to minimize differences in bedding quality between the areas. After the cow-calf pair had been removed, a light cleaning of the calving area was carried out, which included removal of blood, wet straw, and remains of the amniotic sac. In addition, a thorough cleaning was carried out after the first calving in group II, where all soiled sand and straw in a radius of $1 \mathrm{~m}$ of where the amniotic sac broke was removed and replaced with clean sand and straw. This was done to test possible effects on the calving site selection of the subsequent cow.

Within group, all 6 cows were introduced to the calving area at the same time and allowed $24 \mathrm{~h}$ to acclimatize. Two cows calved within this period and were therefore excluded from the experiment, leading to data obtained from 10 cows (i.e., 5 cows in each group). Each calving area was cleaned thoroughly after these 2 calvings, removing all blood, wet straw, and remains of the amniotic sac, and the subsequent calvings occurred 46 and $39 \mathrm{~h}$ after this procedure, respectively.

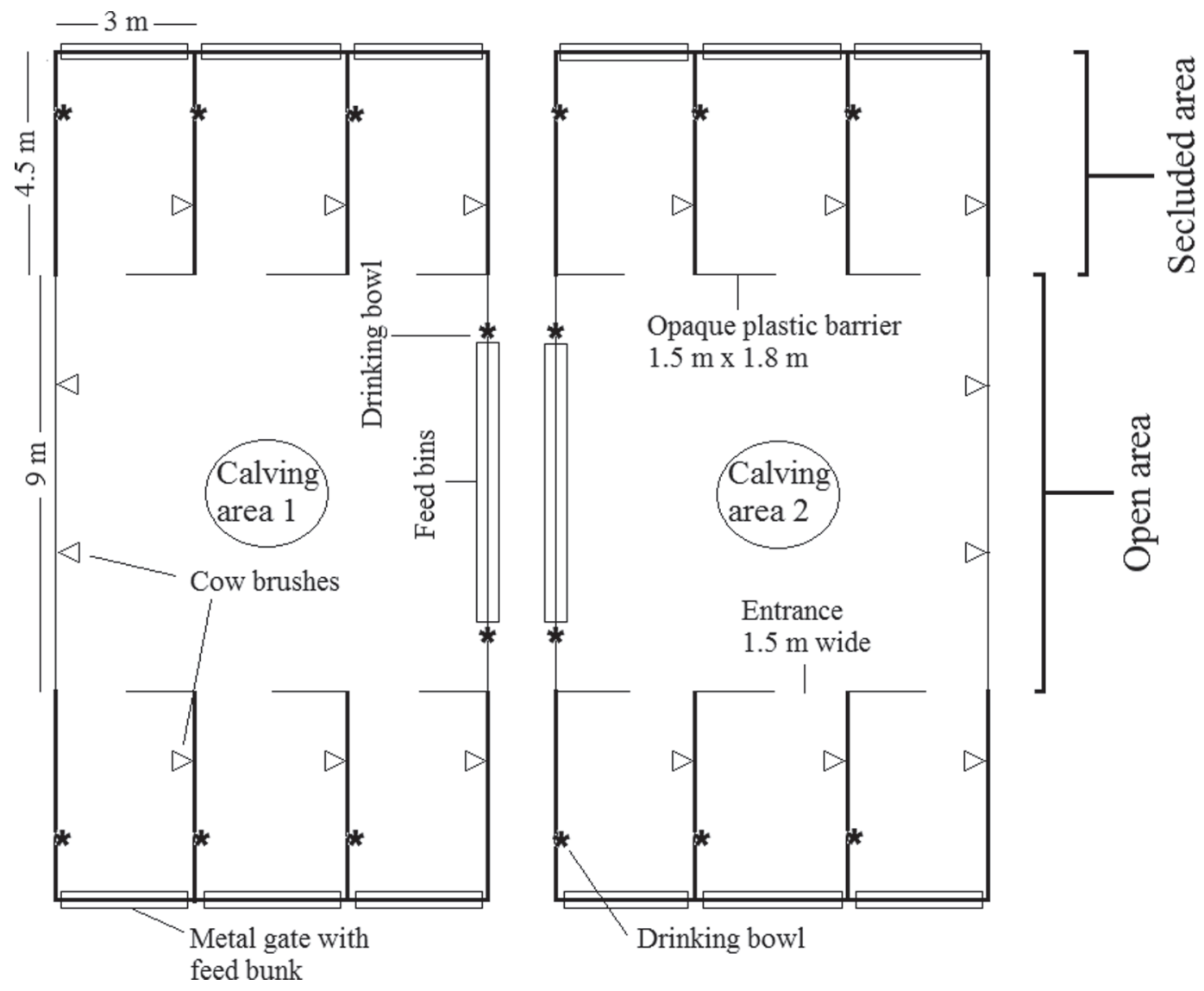

Figure 1. Floor plan of the 2 calving areas in the experimental barn. Thick lines around secluded areas (each $4.5 \times 3 \mathrm{~m})$ represent covered sides made from gray opaque plastic. Position of vertically attached brushes, drinking bowls, and feed bins are shown. 
Table 1. Time difference and physical distance between calvings in groups I and II, respectively

\begin{tabular}{lccccc}
\hline & \multicolumn{2}{c}{ Group I } & & \multicolumn{2}{c}{ Group II } \\
\cline { 2 - 3 } \cline { 5 - 6 } Order of calvings & Time $(\mathrm{h})$ & Distance $(\mathrm{m})$ & & Time $(\mathrm{h})$ & Distance $(\mathrm{m})$ \\
\hline First and second & 16 & $<2.5$ & & $120^{1}$ & $>8^{1}$ \\
Second and third & 27 & $<2.5$ & & 43 & $<2.5$ \\
Third and fourth & 61 & $<2.5$ & & 31 & $<2.5$ \\
Fourth and fifth & 20 & $<2.5$ & & 120 & $<2.5$ \\
\hline
\end{tabular}

${ }^{1} \mathrm{~A}$ thorough cleaning procedure was done after the first calving.

The groups were monitored by digital video cameras (model: TVCCD-624, Monacor, Bremen, Germany) mounted above the calving areas. One camera was mounted above the open area and one above each secluded area; 14 cameras in total. Videos were stored continuously throughout the experimental period, and the behavior of each cow was observed for $24 \mathrm{~h}$ before calving by an experienced observer using these videos. Position, posture, and behavioral elements were recorded using 5-min instantaneous sampling (Martin and Bateson, 2007) to keep track of the calving process. The exact time of calving (when the hips of the calf were fully expelled from the dam) was recorded, and the precise location of the birth was noted as well as the location of the breaking of the amniotic sac. The breaking of the amniotic sac was visible from the video as either the sac breaking outside the cow or as a sudden fluid bursting out of the cow when the sac ruptured inside the cow. To analyze whether the cows calved at random locations, a 1-sample proportion test with continuity correction was used (Teetor, 2011). The statistical analysis was performed using the $\mathrm{R}$ software, version 3.1.2 ( $\mathrm{R}$ Core Team 2014).

In group I, all 5 cows calved in close proximity to each other (Figure 2a and Table 1). The first cow calved in the open area, where her amniotic sac broke. The 4 subsequent cows calved and their amniotic sacs broke within a radius of approximately 1 cow length of where the first cow calved and where her amniotic sac broke (dark gray circle in Figure 2a).

In group II, the first cow calved in the open area (Figure 2b and Table 1), where her amniotic sac also broke. After this calving, all bedding in a radius of 1 $\mathrm{m}$ of where the calving took place was removed and replaced. The second cow calved inside a secluded area (approximately $8 \mathrm{~m}$ away from the first calving, Table 1 ), where her amniotic sac broke. For the 3 subsequent cows, their amniotic sacs broke, and they also calved, within a radius of approximately 1 cow length of the second calving.

In all cases ( 7 out of 10) where no thorough cleaning was carried out, cows calved within a distance of 1 cow length (maximum $2.5 \mathrm{~m}$ ) from where the previous calving had taken place. Statistical testing indicated that the cows did not select calving site by random, but chose to calve in very close proximity to where the previous calving took place $\left(\chi^{2}=5.14\right.$, $\left.\mathrm{df}=1, P=0.023\right)$. Although our study was too small to yield conclusive results, these preliminary observations indicate that choice of calving site may be affected by the site of a previous calving, potentially explained by the presence of amniotic fluid from other cows. The possibility that visual or physical cues affected calving site selection cannot be excluded, but the thorough cleaning after the first calving in group II resulted in a novel site chosen, suggesting that olfaction might outweigh the effects of other cues. The third cow in group II chose to calve on the other side of the barrier from where the previous calving took place (Figure 2b); however, she appeared to do so because no space was left for her in the pen of the previous calving (because this was occupied by 2 other cows when she was due to calve), and she calved in the closest possible proximity to the previous calving site by choosing the nearest corner in the neighboring pen. One might speculate whether all cows in the group were attracted to the calving site and not just cows close to calving. However, a cow's attraction toward amniotic fluid occurs $12 \mathrm{~h}$ before calving and not before that time (Pinheiro Machado et al., 1997); because the other cows in the group calved more than $12 \mathrm{~h}$ after the second calving (Table 1), it is unlikely that these may have been affected by olfactory cues from the previous calving.

If the present findings are confirmed by a larger study, this may have implications for management procedures in the modern dairy industry, especially for the development of motivation-based calving facilities.

\section{ACKNOWLEDGMENTS}

The authors are grateful to the farm staff and the students helping throughout this study. Funding from the Green Development and Demonstration Programme of the Danish Ministry of Food, Agriculture and Fisheries (Copenhagen, Denmark), as well as the Graduate School of Science and Technology, Aarhus University, 
a)

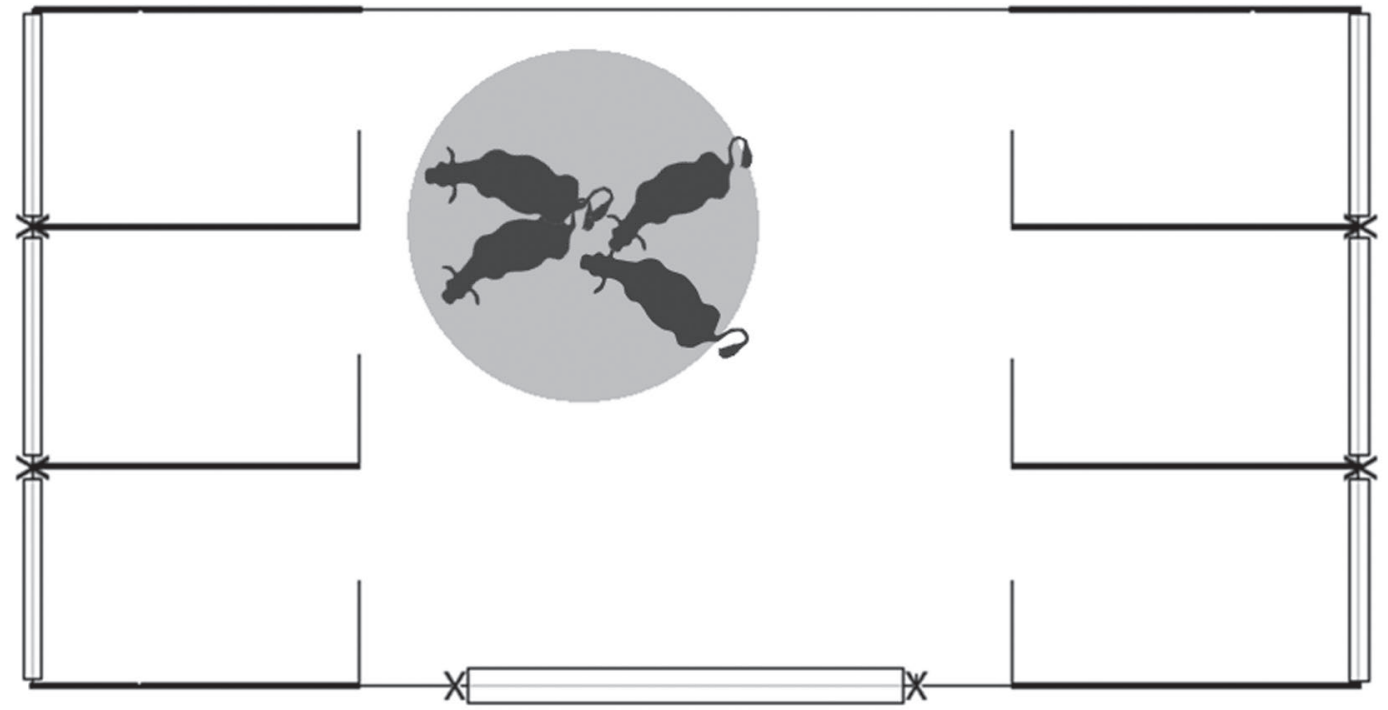

b)

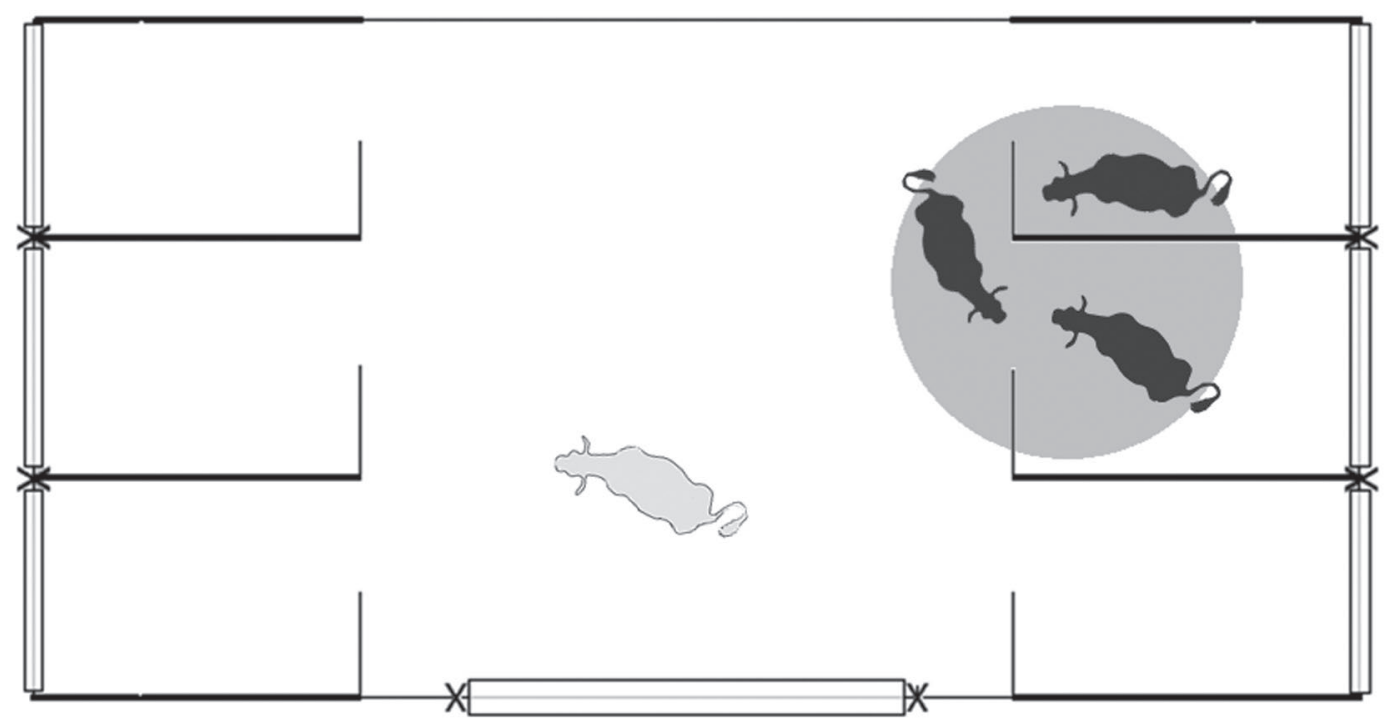

Figure 2. Calving sites in group I (a) and II (b). The center of the large gray circle indicates the calving place of the first cow and the periphery of this circle indicates 1 cow length from where the calving took place (diameter of approximately $2.5 \mathrm{~m}$ ). The black cows illustrate the position of each subsequent calving. In (b) the light gray cow illustrates the position of the first calving cow, after which a thorough cleaning and replacement of sand and straw was carried out.

is gratefully acknowledged. We thank Dan Weary and Nina von Keyserlingk (University of British Columbia, Vancouver, Canada) for fruitful discussions regarding these findings. Last, we thank Jason C. Fisher [University of California, Los Angeles \& Integration and Application Network, University of Maryland (College Park) Center for Environmental Science (ian.umces. edu/imagelibrary/)] for the cow graphics that have been modified and used in the figures.

\section{REFERENCES}

Abade, C. C., J. A. Fregonesi, M. A. G. von Keyserlingk, and D. M. Weary. 2015. Dairy cow preference and usage of an alternative freestall design. J. Dairy Sci. 98:960-965.

Bak, A. S., M. S. Herskin, and M. B. Jensen. 2016. Effect of sand and rubber surface on the lying behavior of lame dairy cows in hospital pens. J. Dairy Sci. 99:2875-2883.

Campler, M., L. Munksgaard, M. B. Jensen, D. M. Weary, and M. A. G. von Keyserlingk. 2014. Short communication: Flooring preferences of dairy cows at calving. J. Dairy Sci. 97:892-896. 
Dunbar, I., E. Ranson, and M. Buehler. 1981. Pup retrieval and maternal attraction to canine amniotic fluids. Behav. Processes 6:249-260.

Edwards, S. A. 1983. The behavior of dairy cows and their newborn calves in individual or group housing. Appl. Anim. Behav. Sci. 10:191-198.

Fabre-Nys, C., P. Poindron, and J. P. Signoret. 1993. Reproductive behavior. Pages 147-194 in Animal Reproduction. G.J. King, ed. Elsevier, Amsterdam, the Netherlands.

Jensen, M. B. 2012. Behaviour around the time of calving in dairy cows. Appl. Anim. Behav. Sci. 139:195-202.

Kristal, M. B. 1991. Enhancement of opioid-mediated analgesia: A solution to the enigma of placentophagia. Neurosci. Biobehav. Rev. 15:425-435.

Lévy, F., P. Poindron, and P. Le Neindre. 1983. Attraction and repulsion by amniotic fluids and their olfactory control in the ewe around parturition. Physiol. Behav. 31:687-692.

Martin, P., and P. Bateson. 2007. Measuring Behaviour: An Introductory Guide. 3rd ed. King's College, Cambridge University Press Cambridge, UK.

Miedema, H. M., M. S. Cockram, C. M. Dwyer, and A. I. Macrae. 2011. Behavioural predictors of the start of normal and dystocic calving in dairy cows and heifers. Appl. Anim. Behav. Sci. 131:14-19.

Pinheiro Machado, F. L. C., J. F. Hurnik, and G. King. 1997. Timing of the attraction towards the placenta and amniotic fluid by the parturient cow. Appl. Anim. Behav. Sci. 53:183-192.
Proudfoot, K. L., M. B. Jensen, P. M. Heegaard, and M. A. G. von Keyserlingk. 2013. Effect of moving dairy cows at different stages of labor on behavior during parturition. J. Dairy Sci. 96:1638-1646.

Proudfoot, K. L., M. B. Jensen, D. M. Weary, and M. A. G. von Keyserlingk. 2014. Dairy cows seek isolation at calving and when ill. J. Dairy Sci. 97:2731-2739.

R Core Team. 2014. R: A Language and Environment for Statistical Computing. R Foundation for Statistical Computing, Vienna, Austria. Accessed Sep. 22, 2016. http://www.R-project.org/.

Reich, L. J., D. M. Weary, D. M. Veira, and M. A. G. von Keyserlingk. 2010. Effects of sawdust bedding dry matter on lying behavior of dairy cows: A dose-dependent response. J. Dairy Sci. 93:1561-1565.

Rørvang, M. V., and M. B. Jensen. 2016. The effect of choice of individual calving pen design on progress of calving in multi-parous dairy cows. Page 14 in Proceedings of The 26th Nordic Regional Symposium of The International Society for Applied Ethology, DCA Report No. 070, January 2016. Aarhus University, Aarhus, the Netherlands.

Teetor, P. 2011. R Cookbook: Proven Recipes for Data Analysis, Statistics, and Graphics. 1st ed. O'Reilly Media Inc., Sebastopol, CA.

Tucker, C. B., D. M. Weary, M. A. G. von Keyserlingk, and K. A. Beauchemin. 2009. Cow comfort in tie-stalls: increased depth of shavings or straw bedding increases lying time. J. Dairy Sci. 92:2684-2690. 